\title{
La oposición por pluspetición a la ejecución del contrato bancario de descuento
}

\author{
Juan Manuel Bermúdez Requena ${ }^{1}$
}

\begin{abstract}
Resumen: Determinados usos bancarios, generalmente aceptados en la práctica por venir amparados en contratos redactados unilateralmente por la propia entidad bancaria, vulneran tanto los derechos del usuario como la propia normativa reguladora del ámbito financiero. Dentro de la amplia variedad de contratos bancarios, nos centramos en el estudio del contrato de descuento, donde tiene especial relevancia el cobro de comisiones por devolución de efectos impagados y la aplicación de un alto interés porcentual en la operación muy superior al interés legal del dinero. En el presente trabajo intentaremos ofrecer algunas soluciones para la defensa del cliente-consumidor frente a las demandas en procesos de ejecución basadas en las pólizas de descuento como título ejecutivo.
\end{abstract}

Palabras clave: Usos bancarios. Contrato de descuento. Comisiones indebidas. Consumidores/ usuarios. Proceso ejecutivo.

\begin{abstract}
Certain banking practice generally accepted to come covered in contracts drawn up unilaterally by the bank itself, violate both user rights as the very rules governing the financial field. Among the wide variety of banking contracts, we focus on the study of contract discount is especially relevant where the charging of fees for repayment of unpaid bills and implementation of a high percentage interest in the operation well above the legal interest of money. In this paper we provide some solutions for the defense customer/ consumer cope with the demands of implementation processes based on discount policies and enforcement.
\end{abstract}

Keywords: Banking practice. Contract discount. Charging of fees for repayment implementation processes

\section{Introducción}

Los contratos bancarios de pólizas de descuento, amparados en su frecuente condición de contratos de adhesión, permiten al predisponente aplicar cláusulas generales que en ocasiones incluso carecen de apoyo legal para su exigencia; traduciéndose en liquidaciones improcedentes

1 Doctor en Derecho. Profesor Asociado de la Universidad Pablo de Olavide (Sevilla). Abogado. 
principalmente por cobro irregular de comisiones de devolución ${ }^{2}$ o intereses desproporcionados.

Controversia que en la práctica se plantea, como bien reflejó la Sentencia de la Audiencia Provincial de Madrid (sección 21ª) n 502/2005 de 13 de octubre, en los siguientes términos:

La cuestión objeto de litigio ante esta Sala es la procedencia, legalidad y justificación de la comisión de devolución de efectos, cuestión ésta controvertida, sobre la que esta Sala ya se ha pronunciado en anteriores ocasiones, en sentencias de 15 de Abril de 2002, o en la más reciente de 19 de Octubre de $2004 \ldots$ en la que se recogían los dos principales argumentos utilizados por los Juzgados y Tribunales para dar respuesta al problema debatido: el posible pacto sobre su devengo y la existencia o no de servicio a retribuir con la misma. ${ }^{3}$

Asunto nada baladí en nuestra actual conyuntura económica como ha denunciado el Presidente de la Asociación de Usuarios de Servicios Financieros (AUSBANC):

En el mes de septiembre de 2008, según datos del Instituto Nacional de Estadística, los efectos de comercio en cartera impagados fueron 513.759 por un importe global de 1.688.097.354 euros a los que hay que sumar los 99.411 efectos de comercio recibidos en gestión de cobro de clientes impagados por un importe de 218.038.330 euros. A tenor de estas cifras, resulta enormemente perjudicial para el tejido empresarial una comisión bancaria irregular que se aplica sobre los efectos impagados al ser devueltos a las empresas emisoras para que estas puedan ejercer los derechos que les correspondan. ${ }^{4}$

2 No siendo la única irregularidad detectada en la práctica a la hora de efectuar las liquidaciones, pues también deberíamos citar la aplicación de intereses abusivos superior a 2'5 veces el interés legal del dinero.

3 Aranzadi, marginal JUR 2005/252248.

4 Sin firmar: "Las entidades cobran comisiones de hasta un 6\% del valor nominal del documento devuelto aunque no responde a ningún servicio distinto al de gestión de cobro encomendada". Puede consultarse en www.ausbanc.com 


\section{Ejecución por el banco y defensa procesal del cliente- consumidor: pluspetición}

\subsection{Objeto y planteamiento}

El incumplimiento de las prestaciones a las que viene obligado el adherente supone que la entidad bancaria pueda iniciar un proceso de ejecución en virtud del artículo 517.2.5 LEC; que otorga naturaleza de título ejecutivo a "las pólizas de contratos mercantiles firmadas por las partes y por corredor de comercio colegiado que las intervenga, con tal que se acompañe certificación en la que dicho corredor acredite la conformidad de la póliza con los asientos de su libro registro y la fecha de éstos".

Frente a tal ejecución, ¿cómo puede defenderse el cliente?

De la normativa que regula la oposición a la ejecución de títulos no judiciales ni arbitrales (artículos 557 y ss LEC), merecería "especial atención la invocación de la pluspetición, que como se deduce del artículo 561 LEC debe entenderse referida al fondo del asunto" ${ }^{5}$ (FLUITERS CASADO, 2003, p. 154)

Instrumento procesal, al amparo del artículo 557.1.3 en relación al 558 ambos de la Ley Rituaria civil, que "puede tener un importante campo de actuación desde el momento que el resultado de la liquidación contenga cantidades improcedentes". (GÓMEZ DE LIAÑO DIEGO, 1998, p. 243)

\subsection{Fundamento}

Pudiera entenderse que la pluspetición "es un peculiar motivo de oposición que debe alegarse de modo concreto y específico". Lo que supone el necesario detalle de "las cantidades que se han pedido en

5 FLUITERS CASADO, R.: "Contratos bancarios. A vueltas con la ejecución”; en AAVV: Contratos bancarios, Fluiters Casado R. y Puyol Montero F.J. dir., "Cuadernos de Derecho Judicial", nº XX, CGPJ, 2003, p. 154.

6 GÓMEZ DE LIAÑO DIEGO, R.: Ejecución de créditos derivados de contratos bancarios, Oviedo, 1998, p. 243. 
exceso, las razones que han conducido a formular esa petición excesiva y la cantidad que se acepta como debida. No puede, por tanto, alegarse la pluspetición de un modo genérico afirmando que existe un exceso en la petición y que es necesario proceder a una liquidación de cuentas." (SABATER MARTÍN, 2001, p. 2.714). Correspondiendo al ejecutado al que corresponde la carga de probar que efectivamente se ha producido un exceso y probar su cuantía.

De tal manera que no puede admitirse una alegación genérica de pluspetición como causa opositora, sino que ha de fundamentarse con precisión el motivo en que se basa el exceso de la cantidad por la que se solicita el despacho de ejecución. Por ello, como novedad legislativa, el artículo 557.2 LEC permite que el ejecutado solicite al tribunal la designación de un perito para que emita dictamen sobre el importe de la deuda.

\subsubsection{Por cobro indebido de comisiones de devolución}

I. Inexistencia de pacto expreso sobre comisiones de devolución.

$\mathrm{Si}$ bien desde el análisis formal de los contratos bancarios, inicialmente "no hay en nuestro ordenamiento jurídico-privado norma alguna que permita afirmar que los contratos bancarios son formales" (BONET SÁNCHEZ, 1998, pp. 98-99), aunque haya que tener en cuenta determinadas excepciones legalmente tasadas, así como lo prevenido en el artículo 1.280 del Código Civil), si bien para Bonet cuestión distinta es la de "la existencia de una serie de normas de carácter administrativo (las normas de trasnparencia bancaria) que exigen que determinados contratos bancarios consten por escrito" a efectos de garantizar los legítimos intereses de la clientela en sus relaciones con las entidades de crédito.

Condición que supone que todos los derechos y obligaciones que pretendan exigir o invocar las partes han de estar claramente previstos en el documento del que surgen las relaciones contractuales.

7 SABATER MARTÍN, A.: AAVV: Comentarios a la Nueva Ley de Enjuiciamiento Civil, tomo III, Barcelona, 2001, p. 2.714.

8 BONET SÁNCHEZ, J. I.: "El contrato bancario"; en AAVV: Contratos bancarios y parabancarios, Nieto Carol V. dir., Valladolid,,1998, pp. 98-99.

9 Op. cit., p. 99. 
Repárese que en la práctrica bancaria el supuesto usual es encontrarse ante contratos de adhesión o contratos masa, cuyo clausulado ha sido redactado de forma unilateral por la entidad de crédito; limitándose el cliente a adherirse al mismo con su firma, por lo debe tenerse en cuenta lo establecido en la Ley 7/1998, de 13 de abril, sobre condiciones generales de la contratación, en el Real Decreto Legislativo 1/2007, de 16 de noviembre, por el que se aprueba el texto refundido de la Ley General para la Defensa de los Consumidores y Usuarios, y finalmente la normativa sobre información y protección de la clientela bancaria que citaremos con reiteración.

De tal modo la Ley 26/1988, de 29 de julio, de Disciplina e Intervención de las Entidades de Crédito, exige en su artículo 48.2.a), que:

los correspondientes contratos se formalicen por escrito [...] para asegurar que los mismos reflejen de forma explícita y con la necesaria claridad los compromisos contraídos por las partes y los derechos de las mismas ante las eventualidades propias de cada clase de operaciones. ${ }^{10}$

A mayor abundancia, no es suficiente únicamente que se refleje la obligación de pago de una comisión, sino que este pacto ha de ser claro y expreso. ${ }^{11}$ Principios informadores del contrato establecidos en protección del cliente, según exige la Orden de 12 de diciembre de 1989 del Ministerio de Economía y Hacienda sobre tipos de interés y comisiones, actuación, información a clientes y publicidad; que desarrolla en este punto a la citada Ley 26/1988 de Disciplina e Intervención de las Entidades Bancarias; estableciendo la Norma Séptima apartado $4^{\circ}$ de la referida Orden:

Los documentos contractuales relativos a las operaciones activas o pasivas en los que intervenga el tiempo, deberán recoger de forma explícita y clara los siguientes extremos:

${ }^{10} \mathrm{http} / / /$ www.bde.es/normativa/circu/circulares-O.htm.

11 Desarrollando así en la materia lo dispuesto para los contratos en general en el artículo 1.288 del Código Civil: "La interpretación de las cláusulas oscuras de un contrato no deberá favorecer a la parte que hubiese ocasionado la oscuridad". 
a)...

b) Las comisiones y gastos repercutibles que sean de aplicación, con indicación concreta de su concepto, cuantía, fechas de devengo y liquidación, así como, en general, cualquier otro dato necesario para el cálculo del importe absoluto de tales conceptos. No serán admisibles, a estos efectos, las remisiones genéricas a las tarifas a que se refiere el número quinto de esa Orden. ${ }^{12}$

Con posterioridad abundó en la cuestión la Circular 8/1990 del Banco de España, relativa a la transparencia de las operaciones y la protección de la clientela de las entidades de crédito (que desarrolla la Orden Ministerial de 12 de diciembre de 1989). Cuya Norma Sexta, apartado c) dispone igualmente que "no serán admisibles las remisiones genéricas a las tarifas". ${ }^{13}$

Desarrollando la referida normativa bancaria, la Sentencia de la Audiencia Provincial de Córdoba (Sección 2a) 314/2002 de 12 de diciembre declaró:

de la citada Ley 26/1998, Orden de 12-12-1989 y Circular del Banco de España de 7-9-1990, modificada posteriormente en 22-7-1994, 27-2-1996 y 27-1-1998 se deduce, entre otras consideraciones, que sin perjuicio de la libertad de contratación los referidos contratos deben formalizarse por escrito concretándose con claridad y precisión las comisiones y gastos que deban abonar los clientes de las entidades bancarias con ocasión de los contratos con ellos concertados, con indicación concreta de su concepto, cuantía y demás circunstancias de devengo, sin que sean admisibles revisiones genéricas ni aceptaciones tácitas. Pues bien en el caso que nos ocupa no resulta acreditado que dicho pacto haya tenido lugar entre las partes del procedimiento, por lo que la aplicación del interés variable... sobre el nominal del efecto responde a unilateral actuación de la entidad bancaria, en la que no cabe subsanar la falta o déficit de intervención del usuario mediante la exhibición de las tarifas vigentes repercutibles a la diversidad de servicios y operaciones financieras, pues representan realidades muy diferentes

\footnotetext{
12 Ibidem supra.
}

13 Ibidem supra. 
la publicidad y hasta entrega del cliente de las correspondientes tarifas y el automatismo en la aplicación de las mismas, y ello a virtud de que en todo caso el alcance de vinculatoriedad de tales tarifas se contrae al ámbito de relaciones entre las entidades bancarias y Cajas de Ahorros con el Banco de España en cuanto este regula u orienta el mercado de productos financieros, más no a los usuarios del mercado. Es decir que las comisiones tan citadas no están debidamente indicadas sino solo por remisión. En consecuencia, no pudiendo tener por cumplimentada y satisfecha la negociación de la entidad bancaria con un cliente en la determinación y concreción de las comisiones y gastos imputables por el servicio.

Señalando la Sentencia de la Audiencia Provincial de Granada $\left(\right.$ sección $\left.3^{a}\right)$ no 245/2000 de 18 de marzo que

"en la normativa expuesta, cobra una singular importancia: «La aceptación en firme del cliente». Declaración de voluntad contractual, que en torno a la comisión discutida, «Comisión por Devolución de efectos», adquiere notoria importancia aquí, en este supuesto.Y se expresa esto, porque en el caso de Litis..., ese pacto sobre «Comisiones de Devolución de efectos» no aparece, no surge (de existir no se habría de discutir), ni tan siquiera como declaración tácita de voluntad (del demandante). Y es que tampoco, y con relación a aquél, se puede mencionar una declaración de voluntad presunta, que se encuadraría dentro del ámbito de las tácitas, ya que no se revela en la Entidad actora, un propósito negocial tendente a hacer efectiva la Comisión que se discute. Así, al rechazarse la comisión por devolución de efectos, por no pactada expresamente y por no admitida se está en el caso de acoger la demanda en cuanto a tal extremo". ${ }^{14}$

Por lo que consideró la Sentencia de la Audiencia Provincial de Madrid (sección 21 ${ }^{\mathrm{a}}$ ) n 502/2005 de 13 de octubre, en su Fundamento de Derecho Tercero:

${ }_{14}$ Aranzadi, marginal 2000/1035. La Sala siguió el mismo razonamiento en su Sentencia 315/2000 de 3 de abril, y 810/2000 de 19 de septiembre. 
En el concreto supuesto que nos ocupa, no podemos admitir, pese a las alegaciones efectuadas por Caja de Madrid, que exista pacto expreso que justifique el devengo de la comisión de descuento a que nos venimos refiriendo, y ello por cuanto que no existe cláusula concreta en la que se conviniera el devengo de tal comisión, sin que la remisión genérica que realiza la cláusula cuarta del contrato de negociación de documentos que vincula a las partes en litigio sea suficiente para considerar existía tal pacto, por cuanto que al margen de no reflejar la misma con la suficiente claridad pacto de devengo de comisión de descuento, no conviniéndose comisión en este concepto, además tampoco se previno su cuantía o modo de cálculo de la misma, ni fecha de su liquidación, no siendo válida la remisión a las "tarifas" a tales efectos, teniendo en cuenta en este punto el contenido tanto de la Orden del Ministerio de Economía y Hacienda de 12 de Diciembre de 1989 (norma 7, apartado $4^{\circ}$. c)) como la Circular 8/1990, de 7 de Septiembre del Banco de España, en los que se dice que a efectos de comisiones y gastos no serán admisibles las remisiones genéricas a tales tarifas.Además es evidente que el cobro de una comisión por la devolución de efectos supone un incremento del precio fijado para el descuento, por lo que tal pacto debe constar con suficiente claridad, y no de forma genérica, en una cláusula general, cuando supone un importante desequilibrio para quien conviene con una entidad bancaria una gestión de cobro, satisfaciendo una remuneración por ella, y que por el resultado de la misma, ajeno como tal a tal gestión, ve incrementado su coste. ${ }^{15}$

Los mencionados principios informadores los encontramos posteriormente incorporados en el Real Decreto Legislativo 1/2007, de 16 de noviembre, por el que se aprueba el texto refundido de la Ley General para la Defensa de los Consumidores y Usuarios y otras leyes complementarias; al disponer en su artículo 80.1.a):

\footnotetext{
15 Aranzadi, marginal JUR 2005/252248. Con anterioridad la misma Sala en su Sentencia 380/2004 de 19 de octubre. Idéntica posición mantuvieron la Sentencia de la Audiencia Provincial de Málaga de (Sección 4ª) 971/2002 de 19 de noviembre, Asturias (Sección 4a) Sentencia de 16 de enero de 2001,
} 
En los contratos con consumidores y usuarios que utilicen cláusulas no negociadas individualmente, incluidos los que promuevan las Administraciones públicas y las entidades y empresas de ellas dependientes, aquéllas deberán cumplir los siguientes requisitos:

a) Concreción, claridad y sencillez en la redacción, con posibilidad de comprensión directa, sin reenvíos a textos o documentos que no se faciliten previa o simultáneamente a la conclusión del contrato, y a los que, en todo caso, deberá hacerse referencia expresa en el documento contractual.

II. Inexistencia de causa contractual que fundamente el cobro.

Dispone el artículo 1.274 del Código Civil que en los contratos remuneratorios se entiende por causa "el servicio o beneficio que se remunera".

La controversia en este punto, que alcanza a la jurisprudencia menor donde la cuestión tampoco es pacífica, ${ }^{16}$ se encuentra en precisar si ante la devolución por impago del efecto descontado tras la oportuna gestión de cobro que efectúa la entidad bancaria, ésta puede repercutir una comisión a su cliente por tratarse de un servicio efectivamente prestado y no retribuido por otro concepto; o por el contrario es una circunstancia incidental que se encuentra cubierta por la retribución contractual pactada en forma de intereses, en cuyo caso se vulneraría el artículo 1275 CC.

De especial interés la Norma tercera de la Circular 8/1990 del Banco de España cuando preceptúa:

${ }_{16}$ Como afirmó la Sentencia de la Audiencia Provincial de Córdoba (sección $2^{\mathrm{a}}$ ) $\mathrm{n}^{\mathrm{o}}$ 270/2006 de 19 de octubre (Aranzadi, marginal JUR 2007/145005): "El tema que se viene a plantear en el recurso es el de la procedencia o no de la comisión por devolución de efectos previamente descontados en entidad financiera que ya ha cobrado una comisión precisamente por ese descuento. En la resolución de esta controversia se han venido dando dos posturas, la primera, que reconoce la legitimidad de esas comisiones en base al principio de libertad de pactos, y la segunda, que se la niega sobre la base de que la devolución del efecto caso de impago no supone ningún tipo de prestación adicional a cargo de la entidad financiera. Estas mismas posiciones se pueden encontrar en otras Audiencias Provinciales, si bien, al igual que en ésta, el criterio de darle validez, viene a ser minoritario". 
Las comisiones y gastos repercutidos deben responder a servicios efectivamente prestados o gastos habidos. En ningún caso podrán cargarse comisiones o gastos por servicios no aceptados o solicitados en firme por el cliente.

Estimamos que para resolver tal cuestión primero debe partirse de la adecuada configuración de la naturaleza jurídica del contrato de descuento.

Cabría conceptuarlo como un "contrato por el cual es descontante se obliga a anticipar al descontatario el importe de un crédito dinerario, contra tercero y de vencimiento futuro pero determinado (o, por excepción, determinable) a cambio de la detracción de un 'interusurium' y eventuales comisiones, y de la enajenación a su favor de un determinado crédito, asumiendo el descontatario la obligación subsidiaria de restitución". ${ }^{17}$ (GARCÍA-PITA Y LASTRES, 1998, p. 642)

Este contrato atípico pudiéramos calificarlo como un mandato al amparo del artículo 1790 del Código Civil, ${ }^{18}$ mediante el cual el banco deberá realizar la gestión de cobro del instrumento que el descontatario le ha entregado 'pro solvendo'. Y en caso de alcanzar el buen fin de la operación, la entidad bancaria deberá cumplir la obligación de rendir cuenta de la actividad desarrollada al cliente-mandante, conforme a la obligación legal establecida en el artículo 1720 del mismo Código (y los artículos 244, 250, 260, 263 y 277 del Código de Comercio).

Por tanto, parece que la comunicación del impago, y cobro de comisión de devolución no responde a un servicio expreso que se aparte del mandato general de cobro o de las obligaciones legales asumidas por el banco-mandatario

Así lo ha entendido entre otras la Audiencia Provincial de Córdoba, que en pleno de fecha 16.6.2006 para unificación de criterios, acordó una postura unitaria sobre este tema; en concreto:

17 "Contrato bancario de descuento y su evolución en la actividad crediticia"; en AAVV: Contratos bancarios y parabancarios, Nieto Carol V. dir., Valladolid, 1998, p. 642.

18 Artículo 1790 CC: "Por el contrato de mandato se obliga una persona a prestar algún servicio o hacer alguna cosa, por cuenta o encargo de otra" 
se vino a aceptar los argumentos de la tesis que niega validez a este tipo de comisiones sobre la base de que no corresponde a prestación alguna adicional al descuento propiamente dicho en cuyo marco o se cobra el efecto o se devuelve al cliente, todo perfectamente previsible cuando se acuerda el descuento, y no responde a otra cosa que a lo que se encuentra obligada la entidad financiera cuando concierta el descuento, por lo que ya cobra su comisión. De esta forma se posiciona en los mismos términos que la Circular del Banco de España sobre transparencia de las operaciones bancarias y protección de la clientela, en detrimento del principio de la autonomía de la voluntad y sobre la base de la exigencia de causa en toda prestación, y sin que se venga a aceptar la aplicación de la doctrina de los actos propios por el descuento y cargo durante un largo periodo de tiempo con aplicación de esas comisiones, al serle inaplicable a la entidad financiera que se encuentra obligada por la Ley de Disciplina e Intervención de Entidades de Crédito y el resto de disposiciones del Banco de España en cumplimiento de los principios señalados en aquélla (Orden de 12.12.1989 y Circular 8/1990), y todo ello ante la posición de prevalencia que en este tipo de contratación mantiene la entidad financiera". ${ }^{19} \mathrm{Y}$ ello porque para la referida Audiencia, "en definitiva, la mera devolución del efecto no supone prestación alguna distinta de la ya contemplada cuando se pactó el descuento y para que la comisión discutida procediera sería precisa que la entidad financiera acreditara cuáles son esas otras prestaciones que generadora de gastos para ella pudiera servir de base para el cobro de esa comisión, sin que a estos efectos baste con la designación genérica de las posibles, respecto de las que no consta su efectiva verificación en el supuesto enjuciado.

Y enlazando con la anterior cuestión del pacto expreso entre las partes (descontante y descontatario) sobre estas comisiones, la propia Audiencia Provincial de Córdoba ya tuvo ocasión con anterioridad de pronunciarse negativamente sobre el cobro de las mismas en su Sentencia 256/2000 de 10 de octubre:

19 Sentencia de la Audiencia Provincial de Córdoba (sección $2^{\mathrm{a}}$ ) n 270/2006 de 19 de octubre (Aranzadi, marginal JUR 2007/145005). 
Cierto es, que, el artículo 1255 del Código Civil, al consagrar el principio de la autonomía de la voluntad, permite que las partes, en los contratos que celebren, puedan establecer los pactos, cláusulas y condiciones que estimen convenientes, pero, siempre que no sean contrarios a la ley, a la moral, o, al orden público, $\mathrm{y}$, en el caso que nos ocupa, el pacto cuyo conocimiento y aceptación se alega, no es legal, ya que, aparte terminar por constituir un sobreprecio añadido al interés o porcentaje del inicial descuento, llevado a la práctica mediante cuantificación ex post facto a su aceptación conceptual, contrario por tanto a la letra y al espíritu del artículo 10 de la Ley de Consumidores y Usuarios al suponer una especie de recargo o penalización a repercutir sobre el cliente por el coste de un algo no imputable al mismo - lo que es contrario a la buena fe y a la equivalencia prestacional -, además, como antes se dice, éste último no sólo no encargó al apelante gestión alguna de cobro, sino ni siquiera actividad interna de la entidad generadora de gastos de devolución, o lo que es lo mismo, no hay servicio prestado de ninguna clase generador de las obligaciones que en otro caso hubieran propiaciado los artículos 244 y siguientes del Código de Comercio, en consecuencia falta la causa. ${ }^{20}$

A modo de conclusión compartimos el criterio de manifestado por la Audiencia Provincial de Barcelona (Sección 17 $7^{\mathrm{a}}$ ), en su Sentencia ${ }^{\circ}$ 144/2004, de 5 de marzo:

El problema no ha recibido una respuesta unánime en la jurisprudencia menor, si bien la opinión mayoritaria es inclina por considerar que las comisiones de devolución no pueden quedar amparadas en el principio de libertad contractual consagrado en el art. $1255 \mathrm{CC}$, porque carecen de causa que las justifique ex arts. 1274 y 1275 CC, ya que, como señala la SAP Sevilla 7 mayo 2001, con cita de las SSAAPP, Córdoba de 15/9/99, Jaén de 25/3/99, Cádiz de 28/4/99 y 30/6/99 y Madrid de 10/5/2000, el mero hecho de comunicar por el Banco al descontatario el impago del efecto no es un nuevo servicio ajeno al propio contrato de descuento cobro de efectos, que ya tiene su justa retribución en las de gestión o de cobro, así como en el importante tipo de interés del propio contrato

20 Aranzadi, marginal JUR 2001/8856. 
de descuento. El servicio que se presta por la entidad bancaria es el de la presentación al cobro de efectos, y ese ya ha sido remunerado, sin que la simple operación material de devolverlo suponga un nuevo servicio, ya que forma parte integrante de la gestión de cobro, según se razona en aquélla. En el mismo sentido se manifiesta la SAP Almería 9 de septiembre de 2002, y éste es también el parecer de este Tribunal, por lo que procede la estimación del recurso en lo relativo a la debiendo el banco demandado reintegrar el importe de la misma, al haberlo cobrado indebidamente. ${ }^{21}$

Idéntica posición, que estimamos la más adecuada a Derecho y a la protección del cliente bancario, mantuvieron las Audiencias Provinciales de Valencia (sección $8^{\text {a }}$ ), Sentencia 708/2006, de 29 de diciembre y 166/2006 de 26 de abril (Sección 9a), Madrid (Sección 12a), sentencia núm. 246/2005 de 19 abril, Málaga (Sección 5ª) Sentencia 77/2004 de 21 de enero, Zaragoza (Sección 2a) Sentencia núm. 278/2006 de 23 mayo, Sevilla Sentencia de fecha 7 de mayo de 2001, entre otras.

\subsubsection{Por intereses abusivos}

Dispone el artículo 19.4 de la Ley 7/1995, de 23 de marzo, de créditos al Consumo:

En ningún caso se podrán aplicar a los créditos que se concedan, en forma de descubiertos en cuentas corrientes a los que se refiere este artículo, un tipo de interés que dé lugar a una tasa anual equivalente superior a 2,5 veces el interés legal del dinero.

Sobre la nulidad de las cláusulas de adhesión que amparan este excesivo y desproporcionado interés moratorio aplicado por la entidad bancaria, puede citarse entre otras la Sentencia de la Audiencia Provincial de Barcelona (Sección 4ª) 698/2005 de 14 de diciembre (RJA marginal JUR 2006/56539):

La Sala considera que estamos ante un típico contrato de adhesión, en el que el consumidor, no puede hacer otra cosa si quiere adquirir un

21 Aranzadi, marginal AC 2004/459. 
bien mediante pago fraccionado que la de aceptar todo el clausulado redactado unilateralmente de antemano por la entidad financiera. Dicho esto, desde la perspectiva del artículo 10 c) 4 y 10.4 de la Ley 26/1984 para la Defensa de Consumidores y Usuarios, en su redacción originaria, e, incluso en la otorgada por la Ley 7/1998, de 13 de abril, de Condiciones Generales de la Contratación, resulta incuestionable que las cláusulas $4^{\mathrm{a}}$ y $6^{\mathrm{a}}$ consignadas en letra pequeña de redacción compleja para cualquier persona de formación media, y al dorso o reverso del documento, son nulas de pleno derecho por abusivas, pues tanto los intereses remuneratorios TAE 35, 9 y TAE 25,8 , como los intereses de demora (2,25 mensual) son más que excesivos, extremadamente superiores a los que para los descubiertos en cuenta se faculta a las entidades bancarias a cobrar según la Ley de Crédito al Consumo 7/95 de 23 de marzo. Desde esta perspectiva, el ya citado artículo 10 de la Ley de Defensa de Consumidores y Usuarios exige para la validez de las cláusulas contractuales, entre otros requisitos, que estén redactadas conforme a los principios de buena fe y justo equilibrio de las contraprestaciones, lo que excluye, según el punto 4 , las condiciones abusivas de créditos.

A tal efecto es necesario que en todo caso se le dé al consumidor la suficiente información, sobre cuál será el coste del crédito no sólo mensual sino anualmente, para así tener un claro conocimiento de qué es lo que paga.

Pues bien, esta información no puede entenderse cubierta con esas cláusulas al dorso estampadas en letra minúscula y difícilmente legible, y además no expresamente firmadas, constando sólo la firma del demandado en el anverso del documento bajo la expresión genérica de que «ratifico que los datos consignados son ciertos y solicito la concesión de un crédito con sujeción al condicionado reflejado en el reverso que expresamente acepto». Más aún cuando el contenido de las cláusulas discutidas respecto de los intereses remuneratorios, cláusula $4^{\mathrm{a}}$, y por demora, cláusula $6^{\mathrm{a}}$, insertos en los mismos son excesivos, pues como indica la sentencia de la AP de Córdoba, sección tercera, de 24 de mayo de 2002 (AC 2002, 1214), existe una desproporción entre el interés fijado y el de mercado en el ámbito del consumo como lo son respectivamente unos intereses TAE de $35,95 \%$ y TAE de $25,8 \%$ en la época en que se suscribió el contrato, y en concreto, en 1998 fijados en torno al 8\%. 


\section{Efectos procesales}

Prima facie la estimación de los motivos descritos, alegados por el ejecutado, conllevaría la nulidad de las cláusulas referidas al tipo de interés porcentual y al cobro de comisiones de devolución, siempre que nos encontremos, como por otra parte es usual, ante estipulaciones de carácter general predispuestas en un contrato de adhesión; naturaleza que habrá que determinarse conforme al artículo 1 de la Ley 7/1998, de 13 de abril, sobre Condiciones generales de la contratación, si ocncurren los presupuestos siguientes:

1. Son condiciones generales de la contratación las cláusulas predispuestas cuya incorporación al contrato sea impuesta por una de las partes, con independencia de la autoría material de las mismas, de su apariencia externa, de su extensión y de cualesquiera otras circunstancias, habiendo sido redactadas con la finalidad de ser incorporadas a una pluralidad de contratos.

2. El hecho de que ciertos elementos de una cláusula o que una o varias cláusulas aisladas se hayan negociado individualmente no excluirá la aplicación de esta Ley al resto del contrato si la apreciación global lleva a la conclusión de que se trata de un contrato de adhesión.

Siendo la nulidad de tales cláusulas el efecto jurídico de las mismas según el artículo 8 del mencionado texto legal:

1. Serán nulas de pleno derecho las condiciones generales que contradigan en perjuicio del adherente lo dispuesto en esta Ley o en cualquier otra norma imperativa o prohibitiva, salvo que en ellas se establezca un efecto distinto para el caso de contravención.

2. En particular, serán nulas las condiciones generales que sean abusivas, cuando el contrato se haya celebrado con un consumidor, entendiendo por tales en todo caso las definidas en el artículo 10 bis y disposición adicional primera de la Ley 26/1984, de 19 de julio, General para la Defensa de los Consumidores y Usuarios. 
Análoga solución a la ya ofrecida por la Ley 7/1995 de Créditos al Consumo, de especial aplicación en la materia objeto de nuestro estudio, en su artículo $3^{\circ}$ :

No serán válidos, y se tendrán por no puestos, los pactos, cláusulas y condiciones establecidos por el concedente del crédito y el consumidor contrarios a lo dispuesto en la presente Ley, salvo que sean más beneficiosos para éste.

Repárese que tal norma únicamente es aplicable a personas físicas que recurran a los intrumentos de financiación "para satisfacer necesidades personales al margen de su actividad empresarial o profesional". ${ }^{22}$

Señalando el artículo 83.1 del Real Decreto Legislativo 1/2007, de 16 de noviembre, por el que se aprueba el texto refundido de la Ley General para la Defensa de los Consumidores y Usuarios y otras leyes complementarias que "las cláusulas abusivas serán nulas de pleno derecho y se tendrán por no puestas".

Sin embargo podemos encontrarnos con que el Tribunal desestime nuestra pretensión de nulidad de la cláusula que fija el tipo de interés porcentual. ${ }^{23}$ A título de ejemplo la Sentencia de la Audiencia Provincial de Lleida (Sección 2a) n n 456/2003 de 25 de octubre:

Deberá tenerse en cuenta la fecha en que se suscribe el contrato (1989) y el interés legal vigente en aquél momento, que osciló entre el 11,5\% y el 10\% durante los años 1989 a 1991, y que resulta notoriamente superior al que rige durante estos últimos años. Con estas referencias, y si bien es cierto que puede considerarse elevado el interés de demora pactado del $22,50 \%$, ello no implica necesariamente la calificación de desproporcionado hasta el punto de representar un

\footnotetext{
22 Artículo 1.1 de la Ley 7/1995, de 23 de Marzo de Créditos al Consumo.

23 Sentencia de la Audiencia Provincial de Barcelona (Sección 14 ${ }^{\mathrm{a}}$ ) no 236/2006 de 2 de noviembre: "no ha habido abuso en este caso, sino que las partes libremente fijaron el interés moratorio que tuvieron a bien al amparo del principio de libertad contractual (art. $1255 \mathrm{CC}$ ), teniendo en cuenta que el contrato base era una póliza de crédito para descuento de efectos comerciales, en las que el interés pactado suele ser más elevado que cuando se trata de simples préstamos”. RJA, marginal JUR 2007/110433.
} 
grave y manifiesto desequilibrio que conduzca a la consideración de la cláusula como abusiva para este tipo de interés.

Por tanto, atendiendo a la fecha de su otorgamiento, al tipo de interés legal del dinero en aquél momento y a los intereses que se abonaban en operaciones análogas en esa misma época, no aprecia la Sala la desproporción y desequilibrio precisos para poder declarar la nulidad, por abusiva, de la cláusula contractual relativa a los intereses. en consecuencia, procede desestimar el recurso y confirmar íntegramente la resolución que es objeto del mismo. ${ }^{24}$

Quedando en ese caso el exceso de computación al ejercicio de la facultad moderadora del Tribunal.

De forma que es conveniente en la práctica que el cliente-ejecutado puede ejercer como pretensión principal la nulidad de la cláusula y total desestimación dela demanda ejecutiva; y subsidiariamente oponerse a tal ejecución alegando pluspetición. Con lo cual, y enlazando con lo establecido en el propio artículo 83 de la Ley General de Defensa de los Consumidores y Usuarios, el título ejecutivo extrajudicial deberá integrarse conforme al artículo 1.258 del Código Civil sin que tal nulidad parcial determine la ineficacia del mismo. ${ }^{25}$

Téngase en cuenta que la pluspletición supone un motivo de oposición, a diferencia de los demás regulados en el artículo 557 LEC (excepto la quita), que no persigue la desestimación íntegra de la demanda ejecutiva sino que la ejecución despachada "se reduzca a los límites cuantitativos que resulten de la alegación y prueba de la misma: el deudor ejecutado admite la existencia y la exigibilidad actual de la deuda pero por una cantidad inferior a la reclamada". ${ }^{26}$

24 RJA, marginal JUR 2004/26422.

25 Artículo 83 del RDL $1 / 2007$ de 16 de noviembre, por el que se aprueba el texto refundido de la Ley General para la Defensa de los Consumidores y Usuarios y otras leyes complementarias.

${ }^{26}$ CORDÓN MORENO F.: en AAVV: Comentarios a la Ley de Enjuiciamiento Civil, tomo II, Cordón Moreno et alii dir., Navarra, 2001, p. 197. Aunque MONTERO AROCA, Derecho Jurisdiccional II Proceso Civil, $16^{\mathrm{a}}$ ed., Valencia, 2007, p. 580, sostiene que "en el auto resolutorio de la oposición por pluspetición cabe que el tribunal estime íntegramente la causa de oposición declarando que no procede la ejecución”. 
En consecuencia la total estimación de la correspondiente excepción da lugar a que continúe la ejecución por la cantidad correcta; ${ }^{27}$ que será determinada por el Juez conforme a la facultad moderadora que le atribuye el artículo 1.154 del Código Civil

Finalmente téngase en cuenta que al ser una oposición respecto al fondo del asunto ha de presentarse en los diez días siguientes al de la notificación del auto que despacha la ejecución.

\section{Referencias}

BONET SÁNCHEZ, J. I.: "El contrato bancario"; en AAVV: Contratos bancarios y parabancarios, Nieto Carol V. dir., Valladolid, 1998, p. 98-99.

CORDÓN MORENO F.: en AAVV: Comentarios a la Ley de Enjuiciamiento Civil, tomo II, Cordón Moreno et alii dir., Navarra, Aranzadi, 2001.

FLUITERS CASADO, R.: "Contratos bancarios. A vueltas con la ejecución”; en AAVV: Contratos bancarios, Fluiters Casado R. y Puyol Montero F.J. dir., "Cuadernos de Derecho Judicial”, n XX, CGPJ, 2003. GARCÍA-PITA Y LASTRES: "Contrato bancario de descuento y su evolución en la actividad crediticia"; en AAVV: Contratos bancarios y parabancarios, Nieto Carol U. dir., Valladolid, Lex Nova, 1998.

GÓMEZ DE LIAÑO DIEGO, R.: Ejecución de créditos derivados de contratos bancarios, Oviedo, Forum, 1998.

MONTERO AROCA, Derecho Jurisdiccional II Proceso Civil, 16 a ed., Valencia, Tirant lo blanch, 2007.

SABATER MARTÍN, A.: AAVV: Comentarios a la Nueva Ley de Enjuiciamiento Civil, tomo III, Barcelona, Iurgium, 2001, p. 2.714.

Enviado em:06/2009 Aprovado em: 10/2009

27 FLUITERS CASADO: ibidem supra. 